\title{
An Approach to Assess Indirect Environmental Effects of Digitalization Based on a Time-Use Perspective
}

Bieser, Jan ; Hilty, Lorenz

\begin{abstract}
The digital transformation has direct and indirect effects on the environment. Direct effects are caused by the production, use and disposal of information and communication technology (ICT) hardware. Indirect effects include the changes to patterns of production and consumption enabled by ICT in other domains. Studies of indirect environmental effects of ICT often focus on individual applications domains and their use cases, which implies that these studies cannot capture systemic effects of ICT adoption. We argue that interaction among ICT use cases is crucial to explain systemic environmental effects of ICT. In order to capture these interactions, we suggest focusing on ICT impacts on individual lifestyles, in particular time use, because (i) time is a limited resource for everyone, a fact which makes time budget constraints a central link among different activities and (ii) many ICT use cases relax time and space constraints of individuals, thus changing time allocation. With this approach, we take into account that individual lifestyles are a major determinant of the overall environmental impact and that ICT diffusion changes individual time-use patterns and therefore lifestyles. Based on these considerations, we propose a conceptual framework that describes the causal mechanisms between ICT use, time-use patterns and environmental impacts.
\end{abstract}

DOI: https://doi.org/10.1007/978-3-319-99654-7_5

Posted at the Zurich Open Repository and Archive, University of Zurich

ZORA URL: https://doi.org/10.5167/uzh-158681

Book Section

Accepted Version

Originally published at:

Bieser, Jan; Hilty, Lorenz (2018). An Approach to Assess Indirect Environmental Effects of Digitalization Based on a Time-Use Perspective. In: Bungartz, Hans-Joachim; Kranzlmüller, Dieter; Weinberg, Volker; Weismüller, Jens; Wohlgemuth, Volker. Advances and New Trends in Environmental Informatics. Cham: Springer (Bücher), 67-78.

DOI: https://doi.org/10.1007/978-3-319-99654-7_5 


\title{
An approach to assess indirect environmental effects of digitalization based on a time-use perspective
}

\author{
Jan C.T. Bieser ${ }^{1}$ and Lorenz M. Hilty ${ }^{1,2}$ \\ ${ }^{1}$ Department of Informatics, University of Zurich, Switzerland \\ ${ }^{2}$ Technology and Society Lab, Empa Materials Science and Technology, Switzerland \\ jan.bieser@ifi.uzh.ch, hilty@ifi.uzh.ch
}

\begin{abstract}
The digital transformation has direct and indirect effects on the environment. Direct effects are caused by the production, use and disposal of information and communication technology (ICT) hardware. Indirect effects include the changes to patterns of production and consumption enabled by ICT in other domains. Studies of indirect environmental effects of ICT often focus on individual applications domains and their use cases, which implies that these studies cannot capture systemic effects of ICT adoption. We argue that interaction among ICT use cases is crucial to explain systemic environmental effects of ICT. In order to capture these interactions, we suggest focusing on ICT impacts on individual lifestyles, in particular time use, because (i) time is a limited resource for everyone, a fact which makes time budget constraints a central link among different activities and (ii) many ICT use cases relax time and space constraints of individuals, thus changing time allocation. With this approach, we take into account that individual lifestyles are a major determinant of the overall environmental impact and that ICT diffusion changes individual time-use patterns and therefore lifestyles. Based on these considerations, we propose a conceptual framework that describes the causal mechanisms between ICT use, time-use patterns and environmental impacts.
\end{abstract}

Keywords: Information and communication technology, ICT, digitalization, indirect environmental impacts, environmental impact assessment, time-use approach, lifestyles.

\section{Introduction}

In September 2015, the United Nations adopted the Sustainable Development Goals, consisting of 17 goals to "end poverty, protect the planet, and ensure prosperity for all" [1, p. 1]. As of October 2017, 195 member states have become party to the Paris Agreement, which "aims to strengthen the global response to the threat of climate change" and to hold "the increase in the global average temperature to well below $2{ }^{\circ} \mathrm{C}$ above pre-industrial levels" [2, p. 2]. A recent report about the status of the $2{ }^{\circ} \mathrm{C}$ target shows that the "gap between the reductions needed and the national pledges made in Paris is alarmingly high" [3, p. xiv], showing the need for further action.

This Accepted Author Manuscript is copyrighted by Springer.

Cite this paper as: Bieser J.C.T., Hilty L.M. (2018) An Approach to Assess Indirect Environmental Effects of Digitalization Based on a Time-Use Perspective. In: Bungartz HJ., Kranzlmüller D., Weinberg V., Weismüller J., Wohlgemuth V. (eds) Advances and New Trends in Environmental Informatics. Progress in IS. Springer, Cham 
The development of digital electronics has led to a convergence among technologies to store, transmit and process information. This process has far-reaching consequences for our patterns of production and consumption [4]. In recent years, "many and diverse domains of social life" increasingly structure "around digital communication and media infrastructures" - a process called "digitalization" [5, p. 1].

Digitalization impacts greenhouse gas (GHG) emissions in two ways:

- On the one side, an increasing amount of ICT hardware is produced, powered with electricity while being used, and finally disposed of - a system of processes which requires resources and causes emissions to the environment (direct effects).

- On the other side, ICT has influence on patterns of production and consumption, with manifold consequences (indirect effects). For example, ICT allows us to work from home and have virtual meetings; thus, avoiding travel-related GHG emissions.

Many studies have been conducted to quantify both direct and indirect effects. Most of these studies conclude that indirect effects are desirable for environmental protection (e.g., reducing GHG emissions) and clearly larger than direct effects (e.g., leading to a significant total reduction of GHG emissions) [6, 7]. For example, the Global e-Sustainability Initiative (GeSI), the ICT industry's association for sustainability, claims that, on a global scale, ICT applications could avoid up to $20 \%$ of annual GHG emissions in 2030 (indirect effect), while the ICT sector will cause roughly $2 \%$ of global GHG emissions (direct effect) [6].

To assess the indirect environmental impact of ICT, most studies estimate the environmental consequences of individual ICT use cases (e.g. e-health or e-learning) or the overarching effect of ICT. However, for the latter, the overarching effect of ICT is often assessed by estimating the aggregated impact of several individual use cases. Such assessments face several methodological challenges, such as defining the baseline, estimating the environmental impact, predicting the future adoption of use cases, estimating rebound effects, or extrapolating from the single use case to societywide impacts [8]. Beyond, the assessment of one or more individual use cases often neglects one crucial phenomenon: interaction among use cases. For example, while a study on telecommuting may show that working from home can avoid work-related trips (and thereby save travel-related GHG emissions), it does not capture how telecommuting in combination with other use cases such as e-commerce, e-health or e-learning might more fundamentally change individual lifestyles. Such changes may only be seen from a more systemic perspective.

Analyzing lifestyles from a time-use perspective can provide a more comprehensive understanding about the indirect environmental impact of ICT including the interaction among use cases because (i) individual lifestyles (how do people spend their time) are a major determinant of environmental impacts, (ii) time is naturally limited and thereby provides a natural constraint to behavior and (iii) most ICT use cases impact individual time use (e.g. e-work, e-health, e-learning, traffic control and optimization reduce travel time). Only few time-use studies in the field of indirect environmental effects of ICT exist. Hence, there is significant potential to 
improve the understanding of indirect environmental effects of ICT by taking a timeuse perspective.

In this paper, we first introduce approaches to assess indirect environmental effects of ICT, discuss the challenge to capture interaction in such assessments, and propose the time-use approach as a promising approach to overcome this challenge. As a first step towards an assessment methodology based on this approach, we introduce a conceptual framework for the interconnection between ICT use, time-use patterns and environmental impact.

\section{Assessment of indirect environmental effects of ICT}

To assess the environmental impacts of ICT, researchers conduct environmental impact assessments (EIAs). The International Association for Impact Assessment states that "Impact assessment, simply defined, is the process of identifying the $[\ldots]$ consequences of a current or proposed action" [9, p. 1]. The Convention on Biological Diversity states that an "Environmental Impact Assessment [...] is a process of evaluating the likely environmental impacts of a proposed project or development, taking into account inter-related socio-economic, cultural and human-health impacts, both beneficial and adverse" [10, p. 1]. According to the European Commission, "Environmental assessment can be undertaken for individual projects, such as a dam, motorway, airport or factory [...] or for public plans or programmes [...]." [11, p. 1]. The target of EIAs is to inform decision makers or the general public about the environmental consequences of certain actions [11]. Beyond, EIAs aim at proposing measures to decision-makers to mitigate unfavorable and promote favorable environmental consequences.

Based on these definitions, we can define the "assessment of indirect environmental effects of ICT" as the process of identifying the future environmental consequences of an ICT solution's capacity to change existing production and consumption patterns, taking into account interrelated socio-economic, cultural and human-health impacts, both beneficial and adverse, with the aim of informing decision-makers or the general public and mitigate unfavorable or promote favorable environmental consequences. Example applications are the change of the design of an ICT solution (e.g. a real-time public transport information system) or the development of a policy for ICT solutions (e.g. about the use of public parking space by carsharing system providers). Such assessments often focus on the promotion of favorable environmental consequences, for example focusing on greenhouse gas abatement potential (the potential to reduce greenhouse gas emissions, e.g. by replacing physical travel with video conferencing). Most assessments estimate the environmental consequences of ICT use cases in specific domains (e.g. e-health, e-learning). Estimations of the overarching effect of ICT often just aggregate the impact of individual use cases. In its "SMARTer 2030" study, GeSI, for example, estimates the global GHG abatement potential of ICT by estimating the GHG abatement potential for 12 individual use cases [6]. In their assessments, researchers apply a variety of 
assessment methods such as system dynamics [12], agent-based modeling [13], the ICT enablement method $[4,6,8,14]$ or life-cycle assessment [15].

\section{Interaction among ICT use cases}

EIAs involve many methodological challenges such as selection of ICT use cases, allocation of impacts to ICT, definition of the baseline, prediction of the future adoption of use cases, estimating rebound effects, and extrapolating from use cases to society-wide impacts [8]. In this study, we focus specifically on one challenge, which is the interaction among use cases.

The "SMARTer" studies by GeSI have been very influential in the area of GHG abatement potentials of ICT [6, 16, 17]. The most recent study, "SMARTer 2030", finds that by 2030 ICT will have the potential to avoid $20 \%$ of global GHG emissions, compared to a baseline scenario assuming no further adoption of ICT solutions [6]. To attain this result, GeSI selected twelve ICT use cases and assessed the GHG abatement potential for each use cases individually (see Fig. 1).

GeSI avoided double counting of GHG abatement potentials between the baseline and use cases and among use cases by deducting GHG abatement potentials which have been considered twice (e.g. the use case e-work avoids travel-related transport, which is part of the total passenger transport volume assumed as a baseline for the use case traffic control and optimization).

However, another form of interaction among use cases has not been considered: If we assume that adoption of all use cases in the "SMARTer 2030" study would achieve $100 \%$, this would imply that by 2030 we would work from home (e-work), shop from home (e-commerce), learn from home (e-learning), bank from home (ebanking) and see the doctor from home (e-health). Not only would such a development result in relatively reclusive lifestyles, which does not seem very plausible, it also contradicts recent observations on the development of passenger transport demand, which, even in Europe, is still increasing [18].

By aggregating the GHG abatement potential of individual use cases, GeSI makes the implicit assumption that each use case affects a closed system which does not interact with other "use case systems". However, use cases do interact, as the following example will illustrate.

A single man works at a company which just introduced telecommuting and decides to work from home on Friday. As dinnertime is approaching, he drives with his car to the next supermarket to buy groceries. Before the introduction of telecommuting, he usually bought the groceries on his way home from work. Hence, telecommuting avoided a work-related trip but induced a shopping-related trip. However, assuming that grocery-home-delivery is offered in his area, he could also have avoided the shopping-related-trip. This is, however, not granted because he may still prefer to go out. This example shows how e-work without and with e-commerce can lead to different outcomes in terms of passenger transport. In general, this means that use cases are not independent systems but interact with each other because ICTs have "diverse and complex impact patterns", "exceptional dynamics of innovation 
and diffusion" and "cross-sector application" [19, p. 1], or in other words: systemic effects. Increasing diffusion of ICT leads to more complex systemic effects, a trend which implies that there will be a growing error if one tries to predict the overall effect by simply aggregating individual ICT use cases. Selected use cases may fundamentally change our patterns of production and consumption, leading to collateral impacts on other use cases. Therefore, in order to estimate the overall, systemic indirect environmental effect of a given set of ICT solutions, one should take a whole-system approach considering the interaction between use cases.

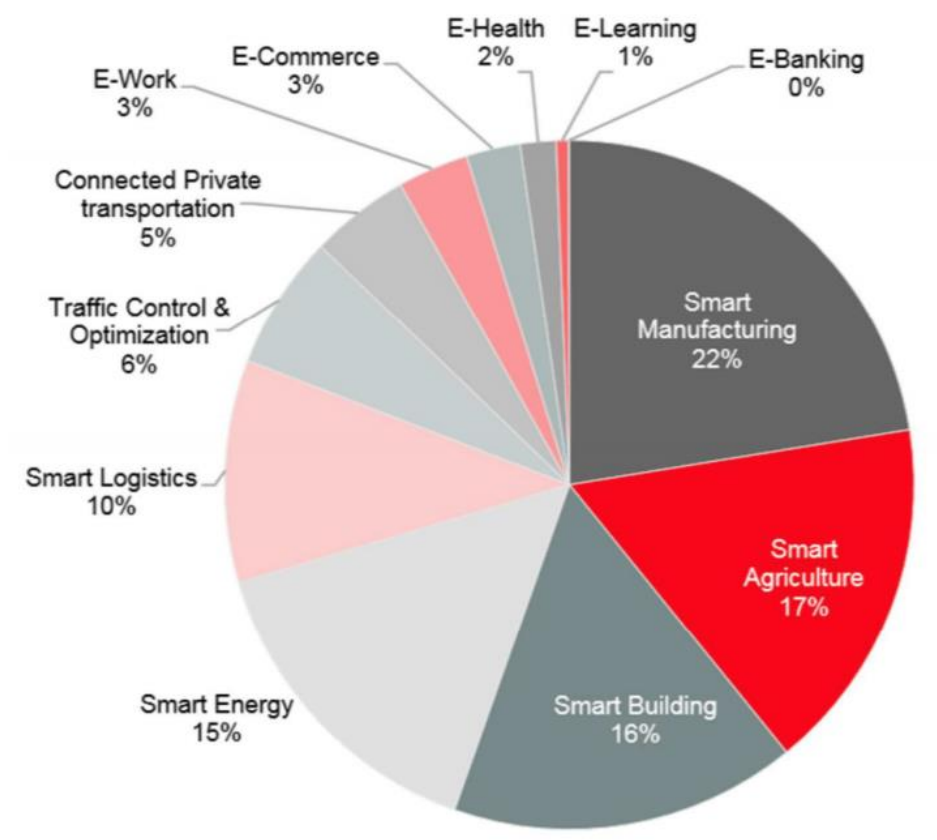

Fig. 1. Share of total GHG abatement potential in 2030 by use case [6].

\section{The time-use approach for the assessment of indirect environmental effects of ICT}

Applying a whole-system approach can be challenging as ICT solutions have various immediate and remote effects on different sectors and aspects of life. Trying to include several use cases along with their interdependencies in one assessment increases the number of entities and relationships to be considered extensively. Such a complex system will have too many unknown parameters and therefore too many degrees of freedom. In order to reduce the complexity, we propose a change of perspective by focusing on time use. 


\subsection{The time-use approach}

A promising approach to consider the interactions among use cases and keeping complexity at a reasonable level is the time-use approach. Instead of analyzing energy or material flows, the time-use approach primarily focusses on individual lifestyles, i.e. the allocation of time of individuals - as members of private households - to everyday activities [20]. Used as a perspective to understand indirect environmental effects of ICT, the time-use approach emphasizes the impacts of ICT on patterns of consumption (How do individuals spend their time?) and the environmental consequences.

In field studies collecting time-use data, individuals usually keep diaries about their daily activities. A large collection of multinational time-use data for various timeframes has been collected and standardized by the Centre for Time Use Research at the University of Oxford since the mid 1980s [21]. To assess the environmental impact of lifestyles, time-use data is commonly linked with data on household expenditure, energy consumption of households, life cycle inventory (LCI) data ${ }^{1}$ and environmentally extended economic input-output tables ${ }^{2}$ [24-27].

\subsection{Assessments of indirect environmental effects of ICT with a time-use approach}

The assessment of indirect environmental effects of ICT can benefit from the time-use approach for two reasons: (i) individual lifestyles are the place where the decisions are made that - via a shorter or longer causal chains - lead to major environmental impacts, and (ii) ICT influences lifestyles by "softening" time and space constraints on activities, thus allowing for changes in individual time allocation [20,28].

What makes the time use an attractive perspective for systems modelling is that time is naturally limited, as every individual, rich and poor, has the same amount of time available ( 24 hours on any given day), in contrast to financial budget, which is unevenly distributed across individuals [29]. First, this makes it easier to compare different lifestyles, and second, it forces the researcher to analyze how changes in time allocation to one activity are compensated with changes in time allocation to other activities. For example, if the researcher finds that telecommuting saves 20 minutes of commuting time per day on average, he or she must also answer the question how the saved time is spent. If we add further ICT use cases to the assessment, they again change the rules of the game in which all activities compete for the same, naturally limited resource - time - with each other. ICT use cases may also add to the list of potential activities themselves: think of computer gaming.

1 Life cycle inventory data is data describing all exchanges (e.g. energy) from and to a technosphere of a product throughout the whole product life cycle. LCI data is used for life cycle assessments and provided by LCI databases, such as ecoinvent [22]

2 An environmentally extended input-output table "depicts the economic transactions between the different sectors and the final demand of a country [...] extended with data on the pollutant emissions and resource uses of the individual economic sectors and the final demand" [23, p. 1]. 
To resume our example from above: When including telecommuting and ecommerce in one assessment, we have to explain how much time individuals save through telecommuting, how much time they save through e-commerce, and how they spend the time saved. The time-use perspective forces us to consider interdependencies between use cases because of the hard 24-hour time budget constraint.

Many ICT use cases discussed in literature have an impact on individual time use. Table 1 provides an overview of the use cases discussed in the "SMARTer 2030" report and their impact on individual time use (detailed information on the "mechanics" of the use cases can be found in the appendix of the report [6]). 7 out of 12 ICT use cases have an immediate impact on time use and the activities performed by individuals, emphasizing that time is a relevant phenomenon to understand ICT impacts. While 5 out of 12 ICT use cases do not immediately impact individual time use, they change the environmental impact of activities performed by individuals. Smart agriculture, for example, changes the production of agricultural goods, thereby changing the environmental burden associated with the activity eating; smart energy changes the integration of renewable energies into the electricity grid and thereby the environmental burden associated with all electricity consuming activities.

Table 1. ICT use cases (based on the "SMARTer 2030" report [6]) and their impact on individual time use.

\begin{tabular}{ll}
\hline Use Case & Impact on time use of individuals \\
\hline Connected Private Transportation & $\begin{array}{l}\text { Reduces travel time through additional transport } \\
\text { services (e.g. car or ride sharing) }\end{array}$ \\
E-Banking & Reduces travel time for banking \\
E-Commerce & Reduces travel time for shopping \\
E-Health & Reduces travel time for health services \\
E-Learning & Reduces travel time for learning \\
E-Work & Reduces travel time for commuting or business trips \\
Smart Agriculture & No impact on individual time use \\
Smart Building & No impact on individual time use \\
Smart Energy & No impact on individual time use \\
Smart Logistics & No impact on individual time use \\
Smart Manufacturing & No impact on individual time use \\
Traffic Control and Optimization & Reduces travel time through more efficient routes \\
\hline
\end{tabular}

Also, time-use data "is a very good anchor for linking other models or information from other data sources" such as location, interaction, expenditure or environmental data [24, p. 823]. By analyzing individual time allocation, we can understand human behavior and decision making in a social context as well as its environmental implications [24]. Finally, time use does not change as fast as other elements of society and provides a solid fundament for analysis and action [20]. 
To date, only few researchers have been applying a time-use approach to assess indirect environmental effects of ICT.

Lenz and Nobis [30] conduct an empirical study about the impact of ICT on fragmentation of activities and travel time using cluster analysis. Fragmentation, as introduced by Couclelis, means the interruption of one activity by another and the subsequent continuation of the former. ICT specifically enables spatial fragmentation (activities can be carried out at different locations), temporal fragmentation (formerly uninterrupted activities are now broken up into pieces which are performed at different times) and fragmentation of the manner of activities (linkage of activities is broken up, e.g. shopping does not require physical trips anymore) [30, 31].

Wang and Law [32] conduct an empirical study using a structural equation model to analyze the impact of ICT use on travel behavior in Hong Kong. They find that the use of ICT leads to more trips and increases the time spent for travel.

Røpke and Christensen [28] use qualitative interviews to show that ICT use leads to a "softening" of time and space constraints of activities and increases the complexity of activities (e.g. simultaneous activities). In that sense, ICT can make activities more energy intensive as it diversifies practices, in particular through multitasking and activation of "dead time".

Hilty et. al. [12] apply System Dynamics to simulate scenarios of the impact of ICT on environmental sustainability within the time horizon 2000-2020. The submodel for passenger transport applies a time-use approach to model the individual choice of different transportation means. In principle, individuals consider the time efficiency $^{3}$ and the prices of different traffic modes (whereby virtual mobility was added as an additional mode to the conventional, physical traffic modes) to choose the optimum mode. If the time efficiency of a mode changes, e.g. congestion slows down individual car traffic or the option to do some work while traveling in public transport saves travel time, the optimum can change, and the modal split will adapt with some inertia in a way that respects the given time budget constraint [12]. The study finds that ICT has an increasing effect on total passenger transport (in passengerkilometers, all physical modes added up) due to two main effects: intelligent transport systems making several physical modes more efficient and "the time utilization effect of mobile ICT applications". Both effects "contribute significantly to passenger transport growth by creating a time rebound effect" [33, p. 1626].

The results of these studies support the notion that a time-use approach is useful for a holistic assessment of indirect environmental effects of ICT.

3 Time efficiency in the model by Hilty et. al. (2004) refers to the amount of people a transport mode can transport over a specific distance in a specific period of time (personkilometers/hour). In case passengers can use traveling time for other purposes (e.g. working on a laptop in a train) this utilized time is deducted from the travel time. In many cases the time utilization potential of transport modes increases through ICT (e.g. in self-driving cars). 


\section{Towards a framework of indirect environmental effects of ICT and individual time use}

Building on evidence that ICT impacts time use and that a time-use approach is a promising perspective to assess indirect environmental effects of ICT, we will develop a first conceptual framework.

One of the largest shares of environmental impacts is caused by construction, use and maintenance of infrastructures (e.g. buildings, streets; other major sectors with environmental impacts include agriculture and manufacturing [34]). Therefore, a strong link between individual lifestyles and environmental impacts is the use of infrastructures. At the same time, many existing and upcoming ICT use cases change individual time-use patterns and thereby also the utilization of existing infrastructures. For example, telecommuting avoids physical commuting trips, directly lowering utilization of transport infrastructure and office buildings. Vice versa, as individuals share infrastructures with other individuals, utilization of infrastructures also affects individual time-use patterns. For example, individuals rather prefer a public transport mode if there are "not many people on the vehicle" [35, p. 483]. In that case, a low utilization of transport infrastructure increases the probability of individuals choosing the respective transport mode; that is, the utilization impacts the time-use patterns. But if utilization drops too low, the frequency of supply may be reduced and demand will further sink due to lower time efficiency. In addition, there are direct links between ICT use and infrastructure utilization, such as intelligent transport systems that directly increase the time efficiency of the transport process. In figure 2, we provide an overview of the causal relationships between ICT use, time-use patterns, infrastructure utilization and environmental impacts.

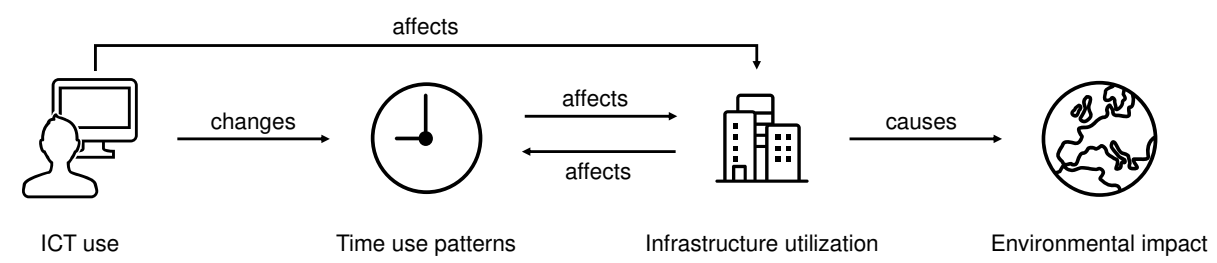

Fig. 2. Causal relationships between ICT use, time-use patterns, infrastructure utilization and environmental impact.

We will illustrate the framework with one concrete example. Bill, an office worker who usually works from the employer's office five days per weeks uses transport infrastructure for his commute, office infrastructure during work and his residential infrastructure during leisure time. Once his employer introduced telecommuting, Bill decides to work from home two days per week, which substantially changes his time allocation, his use of transport, office and residential infrastructure and the associated environmental impact caused by electricity and fuel consumption. On days when he expects the office to be too crowded for focused work, or when he expects significant delays in public transport because of an international event in the city he also decides 
to work from home - so the infrastructure utilization influences his time use. In the long-run, the office worker might even consider moving from the city to a suburb because telecommuting eliminated the need to live close to the employer's office. At the same time, his employer decides to reduce his office space, which is now available for other businesses and might prevent the construction of additional office buildings and the associated environmental impacts. Taking a time-use perspective, we can explain the causal chain from ICT use to lifestyle changes as well as to changes in infrastructure utilization and environmental impact.

\section{Conclusion}

The ongoing digitalization of our daily lives has significant indirect environmental consequences. It mainly depends on these indirect effects whether digitalization will foster or hinder the achievement of global environmental targets. Assessments of indirect environmental effects try to capture these phenomena in order to understand the causal mechanisms behind and develop measures to mitigate unfavorable or promote favorable environmental consequences of digitalization. Most of these assessments highlight the environmental impact of specific ICT use cases. In order to understand broader and long-term indirect effects of ICT adoption (such as rebound effects or lifestyle changes), one also has to consider how use cases interact and cause more fundamental, systemic changes to the existing patterns of production and consumption. By focusing on individual use cases, the prevailing assessment methods cannot assess systemic effects and therefore do not provide a reliable basis for the development of environmental policies with regard to digitalization. To capture systemic effects, we propose applying a time-use approach. Instead of analyzing energy or material flows, the time-use approach focusses on how individuals allocate their time to everyday activities (social practices), assuming that time allocation is the key element of individual lifestyle. The time-use approach is suitable for assessing indirect environmental effects of ICT because (i) individual lifestyles are a major determinant of environmental impacts, (ii) time is naturally limited and thereby provides a natural constraint to behavior, and (iii) most ICT use cases impact individual time use. Also, the time-use perspective allows to assess interaction among ICT use cases in a natural way, as ICT changes fundamental constraints of activities (e.g. e-work allows working from home instead of the employer's office), while all activities compete with each other for the same limited resource - time. Studies assessing indirect environmental effects of ICT with a time-use approach are still scarce. Paying more attention to lifestyles, in particular time use, may add a valuable source of insight to impact assessment methodology and thus may help to develop technologies and policies to reach global environmental targets. 


\section{References}

1. United Nations: Sustainable Development Goals. http://www.un.org/sustainabledevelopment/sustainable-development-goals/, last accessed 2017/11/7.

2. UNFCCC: Paris Agreement. (2015).

3. UNEP: The Emissions Gap Report 2017. A UN Environment Synthesis Report. United Nations Environment Programme (2017).

4. Hilty, L. M., Bieser, J. C. T.: Opportunities and Risks of Digitalization for Climate Protection in Switzerland. University of Zurich, Zurich (2017).

5. Brennen, S., Kreiss, D.: Digitalization and Digitization. In: Culture Digitally. http://culturedigitally.org/2014/09/digitalization-and-digitization/, last accessed 2017/0918.

6. GeSI: \#SMARTer2030. ICT Solutions for 21st Century Challenges. Brüssel (2015).

7. Pamlin, D., Szomolányi, K.: Saving the climate@ the speed of light. First roadmap for reduced $\mathrm{CO} 2$ emissions in the EU and beyond. European Telecommunications Network Operators' Association, WWF (2006).

8. Bieser, J. C. T., Hilty, L. M.: Indirect Effects of the Digital Transformation on Environmental Sustainability. Methodological Challenges in Assessing the Greenhouse Gas Abatement Potential of ICT. Proceedings of the ICT for Sustainability 2018 (2018).

9. International Association for Impact Assessment: Impact Assessment. http://www.iaia.org/, last accessed 2018/04/19.

10. Convention on Biological Diversity: Impact Assessment. https://www.cbd.int/impact/whatis.shtml, last accessed 2018/04/19.

11. European Commission: Environmental Assessment. http://ec.europa.eu/environment/eia/index_en.htm, last accessed 2018/04/19.

12. Hilty, L. M., Wäger, P., Lehmann, M., Hischier, R., Ruddy, T., Binswanger, M.: The future impact ICT on environmental sustainability. Fourth Interim Report. Refinement and Quantification. Institute for Prospective Technological Studies (IPTS), St. Gallen (2004).

13. Xu, M., Allenby, B., Kim, J., Kahhat, R.: A Dynamic Agent-Based Analysis for the Environmental Impacts of Conventional and Novel Book Retailing. Environmental Science \& Technology 43:2851-2857. doi: 10.1021/es802219m (2009).

14. GeSI: Evaluating the carbonreducing impacts of ICT. An assessment methodology. (2010).

15. Moberg, A., Borggren, C., Finnveden, G.: Books from an environmental perspective-Part 2: e-books as an alternative to paper books. The International Journal of Life Cycle Assessment 16:238-246. doi: 10.1007/s11367-011-0255-0 (2011).

16. The Climate Group, GeSI: SMART 2020. Enabling the low carbon economy in the information age. GeSI, The Climate Group (2008).

17. GeSI, The Boston Consulting Group: SMARTer 2020: The Role of ICT in Driving a Sustainable Future. GeSI, The Boston Consulting Group (2012).

18. European Environment Agency: Passenger transport demand. In: European Environment Agency. https://www.eea.europa.eu/data-and-maps/indicators/passenger-transportdemand-version-2/assessment-9. last accessed 2018/04/27.

19. Erdmann, L., Hilty, L.M.: Scenario Analysis: Exploring the Macroeconomic Impacts of Information and Communication Technologies on Greenhouse Gas Emissions. Journal of Industrial Ecology 14:826-834 (2010).

20. Jalas, M.: A Time Use Perspective on the Materials Intensity of Consumption. Ecological Economics 109-123 (2002). 
21. Gershuny, J., Fisher, K.: Multinational Time Use Study. Centre for Time Use Research, University of Oxford (2013).

22. ecoinvent: What does an ordinary dataset look like? - ecoinvent. http://www.ecoinvent.org/support/faqs/first-time-users/what-does-an-ordinary-datasetlook-like.html, last accessed 2017/12/04.

23. Frischknecht, R., Nathani, C., Stolz, P.: Environmentally Extended Input-Output Table for Switzerland 2008 - Greenhouse Gas Emissions (Carbon Footprint). Federal Office for the Environment, treeze, Rütter Soceco (2015).

24. Minx, J. C., Baiocchi, G.: Time Use and Sustainability: An Input-Output Approach in Mixed Units. In: Handbook of Input-Output Economics in Industrial Ecology. Springer, Dordrecht, pp 819-846 (2009).

25. Jalas, M.: The Everyday Life Context of Increasing Energy Demands. Time Use Survey Data in a Decomposition Analysis. Journal of Industrial Ecology 9:129-145. doi: 10.1162/1088198054084644 (2005).

26. Røpke, I., Godskesen, M.: Leisure activities, time and environment. International Journal of Innovation and Sustainable Development 2:155-174. doi: 10.1504/IJISD.2007.016931 (2007).

27. Aall, C., Klepp, I. G., Engeset, A. B., Skuland, S. E., Støa, E.: Leisure and sustainable development in Norway: part of the solution and the problem. Leisure Studies 30:453-476. doi: 10.1080/02614367.2011.589863 (2011).

28. Røpke, I., Christensen T. H.: Energy impacts of ICT - Insights from an everyday life perspective. Telematics and Informatics 29:348-361. doi: 10.1016/j.tele.2012.02.001 (2012).

29. Druckman, A., Buck, I., Hayward, B., Jackson, T.: Time, gender and carbon: A study of the carbon implications of British adults' use of time. Ecological Economics 84:153-163. doi: 10.1016/j.ecolecon.2012.09.008 (2012).

30. Lenz, B., Nobis, C.: The changing allocation of activities in space and time by the use of ICT- "Fragmentation" as a new concept and empirical results. Transportation Research Part A: Policy and Practice 41:190-204. doi: 10.1016/j.tra.2006.03.004 (2007).

31. Couclelis, H.: From Sustainable Transportation to Sustainable Accessibility: Can We Avoid a New Tragedy of the Commons? In: Information, Place, and Cyberspace. Springer, Berlin, Heidelberg, pp 341-356 (2000).

32. Wang, D. Law, F. Y. T.: Impacts of Information and Communication Technologies (ICT) on time use and travel behavior: a structural equations analysis. Transportation 34:513527. doi: 10.1007/s11116-007-9113-0 (2007).

33. Hilty, L. M., Arnfalk, P., Erdmann, L., Goodman, J., Lehmann, M., Wäger, P. A.: The relevance of information and communication technologies for environmental sustainability - A prospective simulation study. Environmental Modelling \& Software 21:1618-1629. doi: 10.1016/j.envsoft.2006.05.007 (2006)

34. European Environment Agency (2016): Sectoral greenhouse gas emissions by IPCC sector. https://www.eea.europa.eu/data-and-maps/daviz/change-of-co2-eq-emissions2\#tab-dashboard-01. last accessed 2018/05/11.

35. Beirão, G., Sarsfield Cabral, J. A.: Understanding attitudes towards public transport and private car: A qualitative study. Transport Policy 14:478-489. doi: 10.1016/j.tranpol.2007.04.009 (2007). 